shape, size and the angulation of the corneal knife (a convenient angle of $45^{\circ}$ to the handle) to manoeuvre the knife safely for the intended purpose. The corneal knife has three cutting sides merged into a round margin with $10 \mathrm{~mm}$ length of the cutting blade. We used the corneal knife for a total and atraumatic release of contracted intrinsic muscles of hand in a post-traumatic intrinsic contracture with good results [Figure 1]. This length is ideal enough to ensure the release intraoperatively, as the surgeon can visualise the cutting end of the blade on the other side of the metacarpal bone across the entire anterior aspect of the metacarpal bone [Figure 1]. In another case, the same knife has been used to create a space for smooth passage of graft material in the case of A2 pulley reconstruction in secondary flexor tendon grafting [Figure 2].

We the authors suggest that a simple technical modification using the corneal knife may be employed in bringing about complete release of interossei muscle and pulley reconstruction in making the surgical procedure easy in an anatomically constrained space.

\title{
Declaration of patient consent
}

The authors certify that they have obtained all appropriate patient consent forms. In the form the patient(s) has/have given his/her/their consent for his/her/their images and other clinical information to be reported in the journal. The patients understand that their names and initials will not be published and due efforts will be made to conceal their identity, but anonymity cannot be guaranteed.

\section{Financial support and sponsorship}

Nil.

\section{The use of corneal blade in hand surgery}

Sir,

We the authors describe a simple method of using a $45^{\circ}$ angled corneal knife for the release of intrinsic muscle and flexor pulley reconstruction.

Corneal knives (ophthalmological microsurgical knife, also called crescent knife) [Figure 1c] (Optiedge India, Ahmedabad), commonly used by ophthalmic surgeons, have sharp edges, straight sides and rounded tips. Moreover, they come in different widths starting from 1.2 to $2.8 \mathrm{~mm}$. Surgeons can take advantage of the

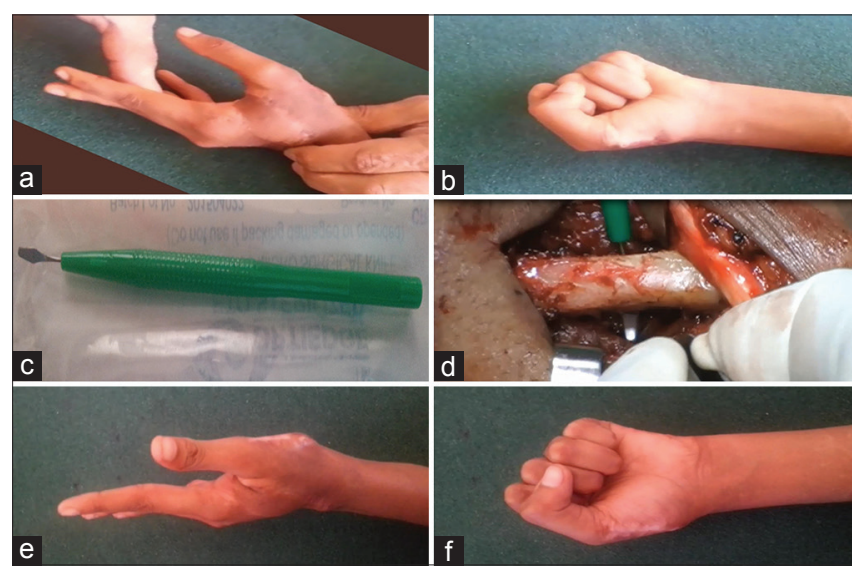

Figure 1: Pre-operative image showing fixed flexion deformity at the metacarpophalangeal joint due to the intrinsic contracture (a) and full flexion of the fingers (b). Ophthalmic microsurgical knife (c). Intraoperative image showing the use of corneal knife for intrinsic release (d). Post-operative image showing adequate correction in extension (e) without loss of flexion (f) 


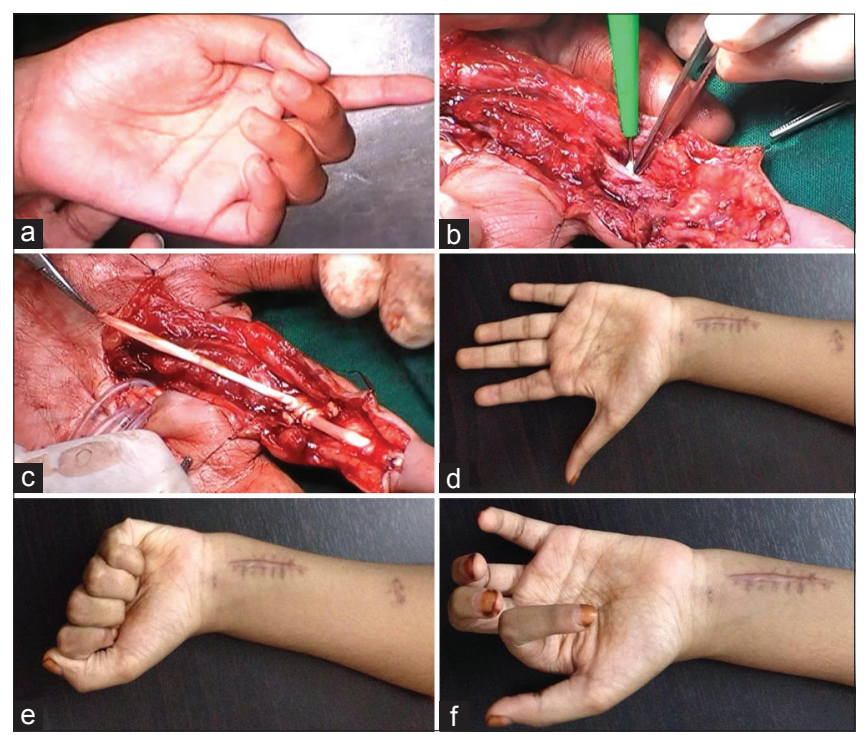

Figure 2: Pre-operative image showing loss of active finger flexion in a flexor digitorum profundus and flexor digitorum superficialis minus index finger (a). Intraoperative image showing the use of corneal knife to create a potential space for passage of the graft (b). Intraoperative image showing reconstructed A2 pulley using 3 loops of palmaris longus (c). Post-operative image showing complete finger extension (d). Three-month post-operative image showing combined and isolated flexion of the index finger (e and f)

\section{Conflicts of interest}

There are no conflicts of interest.

\section{Jagannath Kamath, Nikil Jayasheelan, Sumana Kamath ${ }^{1}$, Premjit Sujir, Rajashekar Danda}

Departments of Orthopaedics and ${ }^{1}$ Ophthalmology, Kasturba Medical College, Manipal University, Mangalore,

Karnataka, India

Address for correspondence: Dr. Nikil Jayasheelan,

Department of Orthopaedics, Kasturba Medical College, Manipal University, Mangalore - 575 001, Karnataka, India. E-mail: dr_nikil@yahoo.com

This is an open access article distributed under the terms of the Creative Commons Attribution-NonCommercial-ShareAlike 3.0 License, which allows others to remix, tweak, and build upon the work non-commercially, as long as the author is credited and the new creations are licensed under the identical terms.

\begin{tabular}{|l|l|}
\hline \multicolumn{2}{|c|}{ Access this article online } \\
\hline Quick Response Code: & Website: \\
\hline
\end{tabular}

How to cite this article: Kamath J, Jayasheelan N, Kamath S, Sujir P, Danda R. The use of corneal blade in hand surgery. Indian J Plast Surg 2017;50:319-20.

๑ 2017 Indian Journal of Plastic Surgery | Published by Wolters Kluwer - Medknow 